\title{
Choice reaction time and the nature of the choice response'
}

\author{
ROBERT GOTTSDANKER, University of Califormia, Santa \\ Barbara, Calif. 93106
}

Difference between choice and simple $R T$ (reaction time) was much smaller on a step-tracking task than on ungraded tasks having similarly direct stimulus-response mapping. Explanation of PR (psychological refractoriness) by noncongruent response organizations was thus supported. On step tracking. choice $R T$ was less than $10 \mathrm{msec}$ longer than simple $R T$, implying that the processing steps either took little more total time or else had overlapping aspects.

In an earlier study concerned with $P R$, an incidental finding was that RT on the four option step-tracking choice was only about $180 \mathrm{msec}$ (Gottsdanker, 1966), about the value which would be expected for simple RT. The present experiment was conducted to find whether the difference between choice and simple RT is indeed lower for step tracking than for other tasks having equally direct stimulus-response mapping. An affirmative answer would have implications for both PR and choice RT. This first study is necessarily preliminary since the potentially important ways in which tasks differ are many.

\section{METHOD}

The three tasks shown in Fig. 1 were compared. On Key Press the choice was made by pressing the appropriate key with the right or left forefinger when, at random, one of the two neon lamps was lighted. Direction choice was made by sliding the handle of a pointer in the direction of the light. On Step Tracking, a horizontal sliding movement of the pointer outward from the center of the display was required with the preferred hand. On each of the two simple conditions of any of the tasks (e.g., right hand on Key Press) the same lamp was lighted throughout a block of trials.

A trial started with the warning lamp, in the center of the display, lighted for $1 \mathrm{sec}$, at which time it was instantaneously replaced by one of the other lamps which was lighted as the signal for response. This lamp remained lighted for $1 \mathrm{sec}$, and then it was instantaneously replaced by the center lamp. Catch trials occurred at random on $10 \%$ of the trials. On such a trial, when the center lamp went off it was not replaced by another lamp.

On Key Press the response closed a light-action microswitch, producing a pulse which was registered on an FM tape recorder. On the other two tasks, movement of the handle activated transducers whose outputs registered displacement, velocity, and acceleration on the tape recorder. Readings were made from reproduced tracings. Details of the apparatus and recording are shown elsewhere (Gottsdanker, 1966, 1967).

Subjects were 11 male and 11 female college students with ages ranging from 16 to 19 . Each task was given as even as possible a division of males and females. Each $\mathrm{S}$ was tested in a single session of about $30 \mathrm{~min}$. This included two blocks of 100 trials under each of the two simple conditions and two blocks under the choice condition, with several orders of counterbalancing between blocks. Brief practice was given before each condition. No information was provided to $S$ on his performance.

\section{RESULTS}

Mean RT was obtained on the two simple conditions for each $S$ and on each option of the choice conditions. RTs of less than $80 \mathrm{msec}$ and erroneous choice responses (which never exceeded $6 \%$ ) were eliminated. Table 1 presents the means across Ss, the mean between-trials SDs, and the between-S
KEY PRESS:
PRESS THE NOICATED KEY
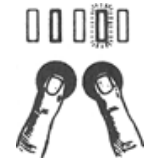

DIRECTION:

MOVE THE POINTER WN THE DIRECTION OF THE LIGHT
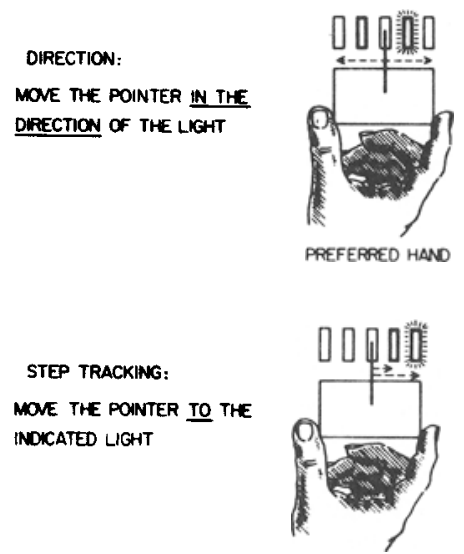

TASK FOR A RIGHT HANDED S

Fig. 1. Displays and required responses on the three tasks. The two options are shown by the heavy lines and one of them is shown as flashing. Dimensions and spacings are not represented according to scale.

SDs. Absolute values on Key Press cannot be compared with those on the other tasks because they include time to close the switch.

As predicted, the overall mean difference between choice and simple RT was less for Step Tracking than for Key Press and Direction: 9.4 vs 36.1 and $31.7 \mathrm{msec}$. Significance is shown in Table 1 by the outcome of the Mann-Whitney ranks test. Choice RT proved to be significantly higher than simple RT on Key Press and Direction as is shown by the outcome of Student's $t$ test. The situation is equivocal for Step Tracking.

While there was an appreciable number of RTs below $80 \mathrm{msec}$ only on the simple condition of Step Tracking,

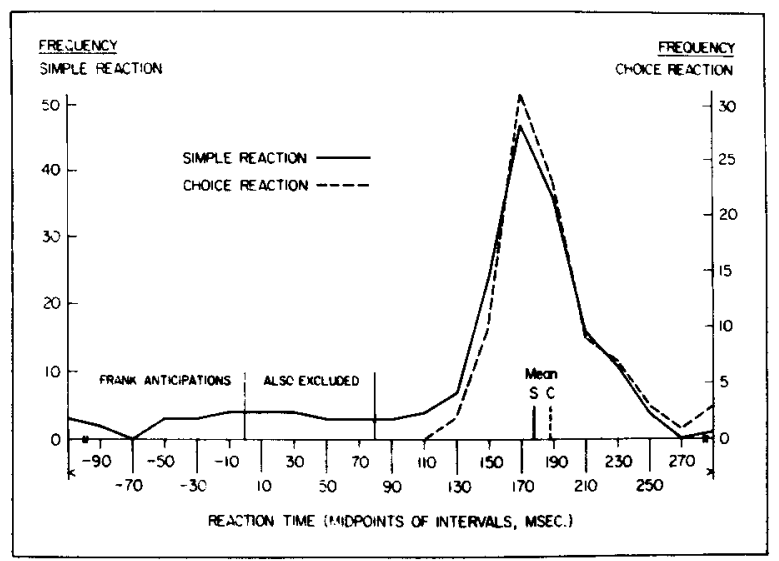

Fig. 2. Frequency distributions for choice and simple "near" trials for $S 15$, who had a high percentage of values below $80 \mathrm{msec}$ on simple trials. Means are shown which exclude values lower than $\mathbf{8 0}$ msec. 
Table 1

Mean RT in Each Condition of the Three Tasks. Statistical Significance is Shown for the Relevant Comparisons. SD, the Between-Trials Index of Variability, is the Square Root of the Mean Between-Trials (within-S) Variances. $\mathrm{SD}_{\mathbf{s}}$ is the Standard Deviation of the Distribution of of Mean RTs for the Different Ss. All Values are in Milliseconds.

\begin{tabular}{|c|c|c|c|c|c|c|c|c|c|}
\hline \multirow[b]{3}{*}{ Condition } & \multicolumn{9}{|c|}{ Task } \\
\hline & \multicolumn{4}{|c|}{ Key Press } & \multicolumn{2}{|c|}{ Direction } & \multicolumn{3}{|c|}{ Step Tracking } \\
\hline & Mean & $S$ & $\mathrm{SD}_{\mathrm{s}}$ & Mean & $\mathrm{SD}_{\mathrm{t}}$ & $\mathrm{SD}_{\mathrm{s}}$ & Mean & $S D_{t}$ & $\mathrm{SD}_{\mathrm{s}}$ \\
\hline \multicolumn{10}{|l|}{ Left or near } \\
\hline Choice & 315.7 & 53.5 & 60.8 & 252.5 & 61.6 & 19.7 & 207.5 & 51.6 & 23.4 \\
\hline Simple & 280.4 & 62.8 & 44.8 & 221.8 & 66.1 & 32.9 & 192.2 & 48.8 & 26.3 \\
\hline Difference & $\begin{array}{c}35.3 \\
\mathrm{p}<.01\end{array}$ & & & $\begin{array}{c}30.7 \\
\mathrm{p}<.05\end{array}$ & & & $\begin{array}{c}15.3 \\
p<.05\end{array}$ & & \\
\hline \multicolumn{10}{|l|}{ Right or far } \\
\hline Choice & 313.7 & 55.6 & 48.5 & 246.0 & 58.4 & 18.6 & 198.6 & 39.3 & 31.9 \\
\hline Simple & 276.9 & 69.9 & 42.3 & 213.3 & 61.3 & 23.9 & 195.1 & 41.1 & 22.1 \\
\hline Difference & 36.8 & & & 32.7 & & & 3.5 & & \\
\hline & $p<.01$ & & & $\mathrm{p}<.01$ & & & n.s. & & \\
\hline \multicolumn{10}{|l|}{ All trials } \\
\hline Choice & 314.7 & & & 249.2 & & & 203.0 & & \\
\hline Simple & 278.6 & & & 217.6 & & & 193.6 & & \\
\hline Difference & 36.1 & $\ldots$ & n.s. & . 31.7 & $\cdots$ & $\mathrm{p}=.01$ & $\ldots 9.4$ & & \\
\hline & $\ldots$ & $\ldots$ & $\ldots \ldots$ & $\because p=.0$ & $14 \ldots$ & $\ldots \ldots$ & $\ldots \ldots$ & & \\
\hline
\end{tabular}

removal of these responses as almost certain anticipations did not distort the overall picture. Figure 2 shows the frequency distributions on near trials for $\mathrm{S} 15$ who shared with two other Ss the highest percentage of simple trials with RTs below $80 \mathrm{msec}(38 \%)$. It is evident that except for the tail on the left for the simple condition, the choice and simple distributions are very similar.

An artifact which suggests itself is that the $S$ on Step Tracking choice adopted the strategy of making the "near" response as soon as a signal appeared and of then going on to the "far" target if he subsequently identified it as the correct choice. A thorough examination was made of this possibility. The relatively few trials where this might have occurred were eliminated from the computations as incorrect responses. A modified response has an entirely different velocity and acceleration pattern than a unitary response. A near-far secondary adjustment was no more difficult to detect than a far-near secondary adjustment. On such a trial the velocity trace shows two peaks instead of one and the acceleration trace shows a more complicated pattern than the characteristic single up and down.

\section{DISCUSSION}

It has previously been argued that the reason PR is lacking in step tracking (i.e., RT to the second of two signals which occur in rapid order is not longer than normal) is that there is the same basic perceptual-motor organization for the successive tasks (Gottsdanker \& Way, 1966; Way \& Gottsdanker, 1968). In key pressing (where PR is always obtained) there is the requirement of effecting a qualitatively new organization along the wake of the preceding one. In step tracking there is the milder demand of adjusting the balance between the same impelling and braking forces in conformity with the new aiming point. The Direction task was included to control for the variable of one vs two hands used on the successive responses. It was assumed that in the absence of a target, the initial organization for the alternative responses would consist largely of mutually exclusive impelling forces. We may term two response organizations "congruent" when they differ only in the modulation of the same components.

If two tasks are congruent it should not be necessary to suppress one organization in order to initiate the other. In choice RT it might even be possible for $\mathrm{S}$ to adopt a motor set. Several writers have pointed out that at least part of the increment generally found for choice over simple RT is a consequence of conflict between the alternative responses (e.g., Woodworth, 1938, p. 331; Berlyne, 1957). The present result may be taken to support the assumption of congruence.

Two broad kinds of explanation are possible of why choice RT was scarcely higher than simple RT on Step Tracking even though there was need for identifying the signal rather than merely detecting it. The first is that the processing steps for choice reaction are but little longer than those for simple reaction if conflict is eliminated. If this is so, the old question of how much more time is required for apperception rather than for mere perception is answered: $10 \mathrm{msec}$ at most. The other kind of explanation is that the processing stages may overlap on step-tracking choices. A suggestion is that processing may continue upon mere detection of the signal if the alternative organizations of response are congruent. The subsequent identification of the signal would then particularize the response.

\section{REFERENCES}

BERLYNE, D. E. Conflict and choice time. British Journal of Psychology, 1957, 48, 106-1 18.

GOTTSDANKER, R. The effect of superseding signals. Quarterly Joumal of Experimental Psy chology, 1966, 18, 236-249.

GOTTSDANKER, $R$. Computer determinations of the effect of superseding signals. Acta Psychologica, 1967, 27, 35-44.

GOTTSDANKER, R., \& WAY, T. C. Varied and constant intersignal intervals in psychological refractoriness. Journal of Experimental Psychology, 1966, 72, 792-804.

WAY, T. C., \& GOTTSDANKER, R. Psychological refractoriness with varying differences between tasks. Journal of Experimental Psychology, 1968, 78, 38-45.

WOODWORTH, R. S. Experimental psychology. New York: Holt, 1938. NOTE

1. This study was supported by Research Grant MH 10447 from the National Institute of Mental Health. I thank R. Ploger who conducted the experimental sessions and T.C. Way, who coordinated analysis of the data. A preliminary report was given at the 1967 meeting of the Psychonomic Society. 